\title{
Diabetes in young adult men: social and health-related correlates
}

Rachel L. Koelmeyer ${ }^{1,2}$, Shyamali C. Dharmage ${ }^{1,3}$ and Dallas R. English ${ }^{1,4^{*}}$

\begin{abstract}
Background: Diabetes is a global public health issue. It is associated with significant disability, morbidity and mortality risks and substantial healthcare costs. Of great concern is the fact that its prevalence is rising, particularly amongst the young, while epidemiological data regarding the incidence, prevalence and complications of earlyonset type 2 diabetes is noted to be sparse.

Methods: We used data from the baseline wave of Ten to Men, a national cohort study of Australian males, to investigate the social and health-related correlates of Australian males aged 18-49 years reporting being diagnosed with diabetes.

Results: The estimated prevalence of a self-reported diabetes diagnosis amongst Australian males aged 18-49 years was $2.95 \%$ (95\% Cl: 2.54-3.43\%). Within this age group, approximately $75 \%$ of those diagnosed with diabetes are expected to be living with a known diagnosis of type 2 diabetes; the remainder are expected to be living with type 1 diabetes. Of the 20 social and health-related factors considered, we found evidence to support the association of eighteen factors after adjusting for age and body mass index. The strongest correlates of reporting a diabetes diagnosis, associated with a $\geq 2$-fold increase in the odds of reporting diabetes were being aged 35-49 years, being unemployed, being obese, seeing a doctor for a check-up more frequently, reporting comorbid high blood pressure or physical or mental health comorbidities and worse self-rated and physical health status.

Conclusion: Australian males aged 18-49 years who are living with a known diagnosis of diabetes are more likely to be socio-economically disadvantaged and suffer substantially worse health status than Australian males aged 18-49 years living without a diabetes diagnosis. Based on the associations detected in this study, older, single males living in regional areas who are socioeconomically disadvantaged, obese and/or who have other comorbidities may be an important subgroup to target for diabetes screening, disease management and prevention efforts.
\end{abstract}

\section{Background}

Diabetes, a chronic condition characterised by high blood glucose levels [1] and associated with a number of serious sequelae such as cardiovascular comorbidities, peripheral neuropathy, retinopathy and kidney disease $[2,3]$, is a global public health concern [4]. In 2015, it was estimated that 415 million people globally were living with diabetes and 5 million deaths were attributable to diabetes [5]. Additionally, health expenditure due to diabetes was estimated at US\$673 million in 2015 [5].

\footnotetext{
* Correspondence: d.english@unimelb.edu.au

${ }^{1}$ Centre for Epidemiology and Biostatistics, The University of Melbourne,

Melbourne, VIC 3010, Australia

${ }^{4}$ Cancer Epidemiology Centre, Cancer Council Victoria, Melbourne 3004, VIC, Australia

Full list of author information is available at the end of the article
}

Onset of type 2 diabetes, the predominant form of diabetes, occurs most commonly in adulthood and is characterised by reduced insulin production and/or reduced insulin responsiveness [1]; in contrast, type 1 diabetes, accounting for approximately $5-10 \%$ of all diabetes cases [6], is characterised by autoimmune destruction of insulin-producing cells and onset occurs most commonly in childhood [1]. Type 2 diabetes is potentially preventable given the role of lifestyle factors such as obesity and lack of physical activity in its pathogenesis [1].

Internationally, the prevalence of type 2 diabetes is rising, particularly in children, adolescents and younger adults [5-8]. Early-onset type 2 diabetes has similar pathophysiology to later-onset diabetes, with both genetic and lifestyle risk factors being implicated $[3,9,10]$. 
However, recent evidence suggests that early-onset diabetes is more aggressive, associated with more rapid decline in beta-cell function, greater likelihood of insulin therapy and greater risk of comorbidities and death [10-13]. Epidemiological data regarding the incidence and prevalence of early-onset type 2 diabetes and its associated complications is sparse [3, 10]. While some international studies have investigated early-onset diabetes [11, 14-17], as far as we are aware, early-onset diabetes has only been specifically investigated in Australia in an Indigenous population [18]. The prevalence of type 2 diabetes is higher in men compared with women [6, 19], making males a priority population for disease prevention efforts.

In this paper, we use data from the baseline wave of Ten to Men, a national longitudinal study on male health, to investigate the social and health-related correlates of selfreported diabetes in younger adult males, with a view to identifying a subgroup of Australian males and priority risk factors to target for disease prevention efforts and optimal management of diabetes in young men.

\section{Methods}

Ten to men

The design, setting and characteristics of participants of the Ten to Men study are reported elsewhere in this issue [20]. In brief, Australian males aged 10-55 years were recruited in 2013 and 2014 via household recruitment from the Australian Statistical Geography Standard (ASGS) [21] major city, inner regional and outer regional areas of Australia. The sampling plan was designed to oversample males living in inner and outer regional areas. The final sample was drawn from 622 SA1s (a sampling unit defined within the ASGS [21]), including 363 major city SA1s, 144 inner regional SA1s and 115 outer regional SA1s. A total of 104,484 households were approached, from which 15,988 Australian males were recruited, resulting in a response fraction of $35 \%$ by confirmed in-scope males.

\section{The current analysis}

This analysis is based on men aged 18 to 49 years at baseline. All participants answered a self-completed questionnaire about their physical and mental health status, healthrelated behaviours, family and social life and health service use. Copies of the questionnaires are available online [22].

\section{Variables}

\section{Outcome variable}

Two questions were asked about diabetes: "Has a doctor or other health professional ever told you that you had this condition?" and "Have you been treated for or had symptoms of this condition in the past 12 months?" For the purpose of this study, diabetes was defined as reporting ever being diagnosed with diabetes by a doctor or health professional. The questions did not differentiate type 1 and type 2 diabetes; however, based on data from the Australian Health Survey, Australia's largest national health survey [23], it is anticipated that approximately one-quarter of respondents in the 18-49 year age group would have been diagnosed with type 1 diabetes and approximately three-quarters would have been diagnosed with type 2 diabetes [24].

\section{Potential correlates}

Sociodemographic variables included age, country of birth, parents' country of birth, region of residence, marital status, highest education level, employment status, before-tax household income and number of life events experienced in the past 12 months. Region of residence was classified in accordance with the ASGS [21].

Health-related behaviour measures included smoking status, fruit and vegetable consumption, level of physical activity in the last week (measured using the Active Australia Survey [25]), body mass index (BMI; derived from selfreported height and weight and classified into healthy weight range or below, BMI $\leq 25 \mathrm{~kg} / \mathrm{m}^{2}$; overweight, BMI $25-<30 \mathrm{~kg} / \mathrm{m}^{2}$; obese, BMI $\geq 30 \mathrm{~kg} / \mathrm{m}^{2}$ or missing), and frequency of visiting a family doctor for a check-up.

Health and wellbeing status variables included self-rated health, the physical component score (PCS) and mental component score (MCS) measures from the SF-12 [26], self-reported lifetime diagnosis of potential comorbidities (angina, anxiety disorder, arthritis, asthma, chronic bronchitis, chronic obstructive pulmonary disease, cancer, cataract, depression, eczema, high blood pressure, high cholesterol, heart attack, heart failure, schizophrenia, sleep apnoea and stroke) and subjective wellbeing, as measured using the Personal Wellbeing Index for Adults (English PWI-A, $4^{\text {th }}$ edition; PWI SWS) $[27,28]$.

\section{Statistical methods}

Descriptive statistics were used to report the proportion of Australian males with particular social and healthrelated characteristics who reported a diabetes diagnosis. The association of the social and health-related variables with reporting diabetes were assessed using logistic regression, with and without adjustment for key type 2 diabetes risk factors (age: age $</ \geq 35$ years; BMI: nonobese, obese and missing). To assess differences in the prevalence of diabetes based on comorbidity status, the proportion of respondents with and without a lifetime diagnosis of each comorbidity who reported diabetes was calculated using survey design commands to adjust for the survey design and apply population weights and then directly standardised to the age distribution of the 2011 Census population of Australian males aged 18-49 
years [29] and using the age groups 18-24 years, 25-34 years, 35-44 years and $45-49$ years. $\chi^{2}$ tests were used to assess the statistical evidence of a difference in the proportions. Missing data were excluded from the analysis except when adjusting for BMI. Most variables had a low level of missing data, with an average proportion of $2.8 \%$ missing data per variable. Four variables had $>5 \%$ missing data: highest education level $(6.5 \%)$, level of physical activity in the last week (10.4\%), BMI (12.7 \%) and before-tax household income (15.8\%). All analyses were conducted using StataSE 13.1 (Stata Corp LP, College Station, TX, USA).

\section{Results}

\section{Prevalence of diabetes in younger Australian males}

There were 11,307 males aged 18-49 years, of whom 11,075 provided data on whether or not they had ever been diagnosed with diabetes $(97.9 \%)$. A history of diabetes was reported by 334 males, of whom $85.6 \%$ reported treatment for or symptoms of diabetes in the 12 months prior to baseline. After taking account of the survey design and using population weights, this equated to an estimated population prevalence of ever being diagnosed with diabetes of $2.95 \%$ (95 \% CI: $2.54-3.43 \%$ ).

\section{Social correlates of reporting diabetes}

Table 1 provides an overview of the social correlates of reporting diabetes, before and after adjusting for age and BMI. Even after adjustment for age and BMI, there was moderate to strong statistical evidence of associations between all social factors other than education and increased odds of reporting diabetes. Particular social characteristics found to be associated with increased odds of reporting diabetes included being aged $\geq 35$ years, being born in or having parents who were born in a country associated with increased risk of diabetes, living in a regional area, being unemployed, reporting a weekly before-tax income of $<$ AU $\$ 100,000$ and having had a higher than average number of life events. The strongest correlates of reporting diabetes, associated with a $\geq 2$ fold difference in the odds of reporting diabetes were being aged 35-49 years and reporting being unemployed.

\section{Health-related correlates of reporting a diabetes diagnosis}

Table 2 provides an overview of the health-related correlates of reporting a diabetes diagnosis, before and after adjusting for age and BMI. All factors considered, other than daily fruit and vegetable consumption, were found to be associated with increased or decreased odds of reporting diabetes, after adjusting for age and BMI. Reporting current smoking, a sedentary lifestyle, obesity, ever being diagnosed with high blood pressure, an above-average number of comorbidities and more frequent check-ups with a doctor were associated with increased odds of reporting diabetes. In contrast, males aged 18-49 years who were in better health (reported good to excellent health, an average or above physical or mental component score and/or an average or above subjective wellbeing score) were substantially less likely to report diabetes, indicating that younger Australian males living with diabetes had significantly worse health and wellbeing status. The strongest health-related correlates of reporting diabetes, associated with a $\geq 2$-fold change in the odds of reporting diabetes were reporting being obese, having other comorbidities, physical health status and frequency of check-ups with their doctor.

\section{Proportion reporting diabetes by comorbidity status}

Table 3 provides details of the proportion of males reporting diabetes based on their comorbidity status. Of the potential comorbidities, there was strong statistical evidence that males who reported being diagnosed with all but two other comorbidities assessed (asthma and eczema), were more likely to report diabetes, after adjusting for age using direct standardisation. This included both physical and mental health comorbidities.

\section{Discussion}

Approximately one in 33 men aged 18-49 years were living with a known diagnosis of diabetes, equating to an estimated population prevalence of $2.95 \%$ in Australian men aged 18-49 years. Of the twenty social and healthrelated factors considered, we found evidence that eighteen were associated with a known diagnosis of diabetes. The strongest correlates of diabetes, associated with a $\geq 2$-fold increase in the odds of diabetes were being aged 35-49 years, being unemployed, being obese, seeing a doctor for a check-up more frequently, reporting comorbid high blood pressure or physical or mental health comorbidities and worse self-rated and physical health status.

Particularly notable findings are the inequities that younger adult males living with diabetes appear to face in terms of their socioeconomic circumstances (more likely to be unemployed and have a lower income) and health status (significantly worse physical and mental health status with greater likelihood of reporting most other comorbidities after adjusting for age distribution), despite still being relatively young. Based on this study, younger adult males living with diabetes are likely to experience a number of comorbidities, both physical and mental, and are therefore likely to have complex healthcare needs. Our findings are generally consistent with other studies in terms of known risk factors for type 2 diabetes [3, 30], increased prevalence of a number of comorbidities commonly associated with diabetes $[5,10,11]$ and the health system burden associated with diabetes [3, 5]. This 
Table 1 Social correlates of reporting diabetes $(n=11,075)$

\begin{tabular}{|c|c|c|c|}
\hline \multirow[t]{2}{*}{ Potential correlate } & \multirow[t]{2}{*}{$\begin{array}{l}\text { Proportion Reporting } \\
\text { Diabetes (\%) }\end{array}$} & \multicolumn{2}{|c|}{$\begin{array}{l}\text { Association with Reporting Diabetes }{ }^{a} \\
\text { Odds Ratio ( } 95 \% \text { Confidence Interval; } p \text { value) }\end{array}$} \\
\hline & & Unadjusted & Adjusted $^{b}$ \\
\hline \multicolumn{4}{|l|}{ Known risk factors } \\
\hline \multicolumn{4}{|l|}{ Age } \\
\hline $18-24$ years, $n=1,951$ & 1.44 & 1.0 (Not Applicable) & 1.0 (Not Applicable) \\
\hline $25-34$ years, $n=3,035$ & 1.55 & $1.08(0.67-1.73 ; 0.748)$ & $1.0(0.62-1.60 ; 0.991)$ \\
\hline $35-44$ years, $n=4,053$ & 3.45 & $2.46(1.63-3.70 ;<0.001)$ & $2.16(1.42-3.27 ;<0.001)$ \\
\hline $45-49$ years, $n=2,036$ & 5.84 & $4.3(2.81-6.47 ;<0.001)$ & $3.61(2.36-5.51 ;<0.001)$ \\
\hline \multicolumn{4}{|l|}{ County of birth } \\
\hline At risk region ${ }^{c}, n=1,245$ & 3.94 & $1.37(1.0-1.87 ; 0.045)$ & $1.75(1.28-2.41 ; 0.001)$ \\
\hline Other country, $n=9,823$ & 2.90 & 1.0 (Not Applicable) & 1.0 (Not Applicable) \\
\hline \multicolumn{4}{|l|}{ Parents' country of birth } \\
\hline Not from at risk region ${ }^{c}, n=9,073$ & 2.90 & 1.0 (Not Applicable) & 1.0 (Not Applicable) \\
\hline One from at risk region ${ }^{c}, n=340$ & 3.24 & $1.12(0.61-2.07 ; 0.717)$ & $1.25(0.67-2.34 ; 0.474)$ \\
\hline Both from at risk region ${ }^{c}, n=1,518$ & 3.62 & $1.26(0.94-1.69 ; 0.127)$ & $1.54(1.14-2.08 ; 0.005)$ \\
\hline \multicolumn{4}{|l|}{ Other Potential Correlates } \\
\hline \multicolumn{4}{|l|}{ ASGS region of residence } \\
\hline Major city, $n=6,503$ & 2.77 & 1.0 (Not Applicable) & 1.0 (Not Applicable) \\
\hline Inner regional, $n=2,510$ & 3.82 & $1.40(1.09-1.80 ; 0.009)$ & $1.29(1.0-1.67 ; 0.048)$ \\
\hline Outer regional, $n=2,053$ & 2.83 & $1.02(0.76-1.38 ; 0.891)$ & $0.90(0.67-1.22 ; 0.503)$ \\
\hline \multicolumn{4}{|l|}{ Marital status } \\
\hline Married/de facto rel., $n=7,136$ & 3.11 & 1.0 (Not Applicable) & 1.0 (Not Applicable) \\
\hline Previously married, $n=555$ & 4.86 & $1.59(1.06-2.40 ; 0.026)$ & $1.40(0.92-2.11 ; 0.114)$ \\
\hline Never married, $n=3,308$ & 2.51 & $0.80(0.62-1.03 ; 0.090)$ & $1.44(1.08-1.92 ; 0.013)$ \\
\hline \multicolumn{4}{|l|}{ Highest education level } \\
\hline Bachelor degree or higher, $n=2,788$ & 2.73 & 1.0 (Not Applicable) & 1.0 (Not Applicable) \\
\hline Non-degree qualification, $n=4,836$ & 3.02 & $1.11(0.84-1.47 ; 0.464)$ & $0.92(0.69-1.23 ; 0.575)$ \\
\hline Secondary school or less, $n=2,766$ & 3.25 & $1.20(0.88-1.64 ; 0.249)$ & $1.13(0.82-1.56 ; 0.449)$ \\
\hline \multicolumn{4}{|l|}{ Employment status } \\
\hline Employed, $n=9,292$ & 2.49 & 1.0 (Not Applicable) & 1.0 (Not Applicable) \\
\hline Unemp. (looking for work), $n=962$ & 5.30 & $2.20(1.61-3.0 ;<0.001)$ & $2.75(1.99-3.80 ;<0.001)$ \\
\hline Unemp. (not looking), $n=589$ & 6.96 & $2.93(2.08-4.14 ;<0.001)$ & $2.94(2.07-4.20 ;<0.001)$ \\
\hline \multicolumn{4}{|l|}{ Before-Tax Income } \\
\hline AU\$100 K+, $n=4,422$ & 2.40 & 1.0 (Not Applicable) & 1.0 (Not Applicable) \\
\hline AU\$60 K - < AU\$100 K, n=2,637 & 3.19 & $1.34(1.0-1.79 ; 0.048)$ & $1.39(1.03-1.86 ; 0.029)$ \\
\hline$<\mathrm{AU} \$ 60 \mathrm{~K}, n=2,291$ & 3.97 & $1.68(1.27-2.24 ;<0.001)$ & $1.93(1.44-2.59 ;<0.001)$ \\
\hline Above-average number of life events, $n=163$ & 3.18 & $1.14(0.92-1.43 ; 0.236)$ & $1.28(1.02-1.60 ; 0.035)$ \\
\hline
\end{tabular}

Where not stated, the reference category is the absence of the characteristic

${ }^{\mathrm{b}}$ After adjusting for age and body mass index

${ }^{c}$ Countries/regions associated with increased risk of diabetes: Asia, Middle East, North Africa or Southern Europe

includes the association of worse socioeconomic status [31], cardiovascular comorbidities [11] and worse physical and mental health with a known diabetes diagnosis [32]. Our study is unusual in terms of exploring the association of diabetes with a more general set of comorbidities and health status measures and exploring socioeconomic correlates in greater depth.

This study has some limitations. Our analyses were based on self-report data, such that some respondents may have been misclassified as living without diabetes or 
Table 2 Health-related correlates of reporting diabetes $(n=11,075)$

\begin{tabular}{|c|c|c|c|}
\hline \multirow[t]{2}{*}{ Potential correlate } & \multirow[t]{2}{*}{$\begin{array}{l}\text { Proportion Reporting } \\
\text { Diabetes (\%) }\end{array}$} & \multicolumn{2}{|c|}{$\begin{array}{l}\text { Association with Reporting Diabetes }{ }^{\mathrm{a}} \\
\text { Odds Ratio ( } 95 \% \text { Confidence Interval; } p \text { value) }\end{array}$} \\
\hline & & Unadjusted & Adjusted $^{\mathrm{b}}$ \\
\hline \multicolumn{4}{|l|}{ Known Risk Factors } \\
\hline \multicolumn{4}{|l|}{ Smoking status } \\
\hline Never smoked, $n=6,320$ & 2.52 & 1.0 (Not Applicable) & 1.0 (Not Applicable) \\
\hline Ex-smoker, $n=2,415$ & 3.81 & $1.53(1.18-1.99 ; 0.001)$ & $1.17(0.90-1.53 ; 0.251)$ \\
\hline Current smoker, $n=2,175$ & 3.72 & $1.50(1.14-1.97 ; 0.004)$ & $1.38(1.04-1.81 ; 0.024)$ \\
\hline Less than daily fruit/veg. consumption, $n=415$ & 3.86 & $1.30(0.78-2.17 ; 0.316)$ & $1.31(0.78-2.21 ; 0.306)$ \\
\hline \multicolumn{4}{|l|}{ Physical activity level } \\
\hline Sufficient for health, $n=5,663$ & 2.38 & 1.0 (Not Applicable) & 1.0 (Not Applicable) \\
\hline Insufficient for health, $n=2,917$ & 2.91 & $1.23(0.93-1.62 ; 0.142)$ & $1.03(0.78-1.36 ; 0.825)$ \\
\hline Sedentary, $n=1,381$ & 5.14 & $2.22(1.65-2.98 ;<0.001)$ & $1.66(1.23-2.25 ; 0.001)$ \\
\hline \multicolumn{4}{|l|}{ BMl } \\
\hline Healthy range or less, $n=3,340$ & 1.53 & 1.0 (Not Applicable) & 1.0 (Not Applicable) \\
\hline Overweight, $n=4,116$ & 2.02 & $1.33(0.93-1.89 ; 0.115)$ & $1.12(0.78-1.59 ; 0.537)$ \\
\hline Obese, $n=2,235$ & 6.76 & $4.67(3.39-6.45 ;<0.001)$ & $3.83(2.77-5.31 ;<0.001)$ \\
\hline Missing, $n=1,384$ & 3.54 & $2.37(1.59-3.52 ;<0.001)$ & $2.35(1.58-3.50 ;<0.001)$ \\
\hline High blood pressure (ever), $n=1,468$ & 10.22 & $6.30(5.02-7.90 ;<0.001)$ & $4.38(3.44-5.56 ;<0.001)$ \\
\hline \multicolumn{4}{|l|}{ Other Potential Correlates } \\
\hline Reported good to excellent self-rated health, $n=10,153$ & 2.22 & $0.17(0.13-0.21 ;<0.001)$ & $0.23(0.18-0.29 ;<0.001)$ \\
\hline Average or above SF-12 PCS, $n=6,640$ & 1.54 & $0.27(0.22-0.35 ;<0.001)$ & $0.35(0.27-0.45 ;<0.001)$ \\
\hline Average or above SF-12 MCS, $n=6,320$ & 2.37 & $0.60(0.48-0.76 ;<0.001)$ & $0.62(0.50-0.78 ;<0.001)$ \\
\hline Average or above PWI SWS, $n=6,378$ & 2.09 & $0.46(0.36-0.57 ;<0.001)$ & $0.51(0.41-0.64 ;<0.001)$ \\
\hline Above-average number of comorbidities, $n=3,545$ & 6.01 & $4.19(3.32-5.28 ;<0.001)$ & $3.28(2.59-4.15 ;<0.001)$ \\
\hline \multicolumn{4}{|l|}{ Check-up with doctor } \\
\hline Never, $n=4,019$ & 0.90 & 1.0 (Not Applicable) & 1.0 (Not Applicable) \\
\hline Less than yearly, $n=2,925$ & 1.68 & $1.89(1.22-2.91 ; 0.004)$ & $1.75(1.13-2.70 ; 0.012)$ \\
\hline Yearly, $n=2,175$ & 2.90 & $3.30(2.18-4.99 ;<0.001)$ & $2.82(1.86-4.27 ;<0.001)$ \\
\hline More than once a year, $n=1,528$ & 11.26 & $14.0(9.75-20.2 ;<0.001)$ & $11.0(7.63-15.9 ;<0.001)$ \\
\hline
\end{tabular}

${ }^{a}$ Where not stated, the reference category is the absence of the characteristic

${ }^{\mathrm{b}}$ After adjusting for age and body mass index

another comorbidity since they may experience the condition without a formal diagnosis. Furthermore, a self-reported diagnosis may not always represent clinically-important disease (for example, a patient experiencing symptoms of depression without meeting clinical thresholds for depression). Additionally, since the study questionnaire did not distinguish type 1 diabetes from type 2 diabetes and given the expected ratio of type 1:type 2 diabetes cases of 1:3, even though our study focused on factors that are associated with type 2 diabetes $[3,5,30]$; it is likely that the strength of the association of such factors with type 2 diabetes has been under-estimated in this study.

A further limitation is that since this study is based on cross-sectional and lifetime frequency data, we cannot be certain which of the associated factors are causes of diabetes, sequelae of diabetes or concurrent experiences. However, based on the findings of our study, assessing how diabetes impacts on socioeconomic status and whether a reported diagnosis of diabetes predisposes younger adult men to other comorbidities beyond commonly-associated conditions such as cardiovascular comorbidities warrants further investigation using longitudinal data.

\section{Conclusions}

Australian males aged 18-49 years and living with a diabetes diagnosis are more likely to be socio-economically disadvantaged and suffer worse health status than Australian males aged 18-49 years who are living 
Table 3 Differences in proportion reporting diabetes by comorbidity status $(n=11,075)$

\begin{tabular}{|c|c|c|c|c|c|}
\hline \multirow[t]{3}{*}{ Potential comorbidity } & \multicolumn{4}{|c|}{ Potential comorbidity status } & \multirow{3}{*}{$\begin{array}{l}\text { Evidence of difference } \\
\text { in proportion with diabetes } \\
P \text { value from } x 2 \text { test }\end{array}$} \\
\hline & \multicolumn{2}{|c|}{ Never diagnosed } & \multicolumn{2}{|c|}{ Lifetime diagnosis } & \\
\hline & $\begin{array}{l}\text { Number of } \\
\text { respondents }\end{array}$ & $\begin{array}{l}\text { \% with early-onset } \\
\text { diabetes }^{\mathrm{a}}\end{array}$ & $\begin{array}{l}\text { Number of } \\
\text { respondents }\end{array}$ & $\begin{array}{l}\text { \% with early-onset } \\
\text { diabetes }^{\mathrm{a}}\end{array}$ & \\
\hline Angina & 10,941 & 2.5 & 98 & 17.5 & $<0.001$ \\
\hline Anxiety disorder & 9,595 & 2.3 & 1,440 & 4.1 & $<0.001$ \\
\hline Arthritis & 10,160 & 2.4 & 876 & 5.2 & $<0.001$ \\
\hline Asthma & 8,487 & 2.5 & 2,548 & 3.0 & 0.215 \\
\hline Cancer & 10,806 & 2.4 & 231 & 12.3 & $<0.001$ \\
\hline Cataract & 10,960 & 2.5 & 86 & 15.1 & $<0.001$ \\
\hline Chronic bronchitis & 10,537 & 2.4 & 486 & 5.1 & $<0.001$ \\
\hline $\begin{array}{l}\text { Chronic Obstructive } \\
\text { Pulmonary Disease }\end{array}$ & 10,993 & 2.5 & 50 & 18.2 & $<0.001$ \\
\hline Depression & 8,977 & 2.0 & 2,070 & 5.2 & $<0.001$ \\
\hline Eczema & 9,825 & 2.5 & 1,207 & 3.0 & 0.320 \\
\hline Heart attack & 10,972 & 2.4 & 81 & 28.7 & $<0.001$ \\
\hline Heart failure & 10,998 & 2.5 & 49 & 35.5 & $<0.001$ \\
\hline High blood pressure & 9,579 & 1.7 & 1,468 & 8.7 & $<0.001$ \\
\hline High cholesterol & 9,608 & 1.7 & 1,435 & 7.7 & $<0.001$ \\
\hline Schizophrenia & 10,952 & 2.4 & 84 & 16.9 & $<0.001$ \\
\hline Sleep apnoea & 10,199 & 2.2 & 841 & 8.2 & $<0.001$ \\
\hline Stroke & 10,984 & 1.9 & 60 & 19.0 & $<0.001$ \\
\hline
\end{tabular}

Proportion adjusted for survey design characteristics and then standardised based on the age distribution of Australian males aged $18-<50$ years based on the 2011 Census

without a diabetes diagnosis. Based on the associations detected in this study, single males living in regional areas who are socioeconomically disadvantaged and/or inactive or obese or who have other comorbidities may be an important subgroup to target for diabetes screening, disease management and prevention efforts.

\section{Abbreviations}

ASGS: Australian Statistical Geography Standard; BMI: Body mass index; MCS: SF-12 mental component score; PCS: SF-12 physical component score; PWI SWS: Personal wellbeing index subjective wellbeing score; PWI-A: Personal wellbeing index for adults

\section{Acknowledgements}

The research on which this paper is based on was conducted as part of the Australian Longitudinal Study on Male Health by the University of Melbourne. We are grateful to the Australian Government Department of Health for funding and to the boys and men who provided survey data.

\section{Declaration}

Publication of this article was funded by the Ten to Men Study. This article has been published as part of BMC Public Health Vol 16 Suppl 3, 2016: Expanding the knowledge on male health: findings from the Australian Longitudinal Study on Male Health (Ten to Men). The full contents of the supplement are available online at https://bmcpublichealth.biomedcentral.com/articles/supplements/ volume-16-supplement-3.

\section{Availability of data and materials}

Ten to Men response data are available to researchers via a request and review process. Information on accessing Ten to Men data is available at http://www.ten tomen.org.au/index.php/researchers.html.Copies of Wave 1 questionnaires, Wave 1 data books, and the Ten to Men Data User's Manual are also available at that site.
Enquires about potential collaborations including sub-studies involving members of the Ten to Men cohort can be addressed to the Study Coordinator at info@tentomen.org.au.

\section{Authors' contributions}

RK, DE and SD were responsible for the analytical design. RK undertook data analysis. RK, DE and SD were involved in interpreting the analysis. RK drafted the manuscript. All authors undertook critical revision of the manuscript and have approved this manuscript version for submission.

\section{Competing interests}

The authors declare that they have no competing interests.

\section{Consent for publication}

Not applicable.

\section{Ethics approval and consent to participate}

The Australian Longitudinal Study on Male Health was approved by the University of Melbourne Human Research Ethics Committee (HREC 1237897 \& 1237376). Participants provided written consent for their participation.

\section{Author details}

${ }^{1}$ Centre for Epidemiology and Biostatistics, The University of Melbourne, Melbourne, VIC 3010, Australia. ${ }^{2}$ School of Clinical Sciences at Monash Health, Monash University, Clayton 3168, VIC, Australia. ${ }^{3}$ Murdoch Childrens Research Institute, Parkville 3052, VIC, Australia. ${ }^{4}$ Cancer Epidemiology Centre, Cancer Council Victoria, Melbourne 3004, VIC, Australia.

Published: 31 October 2016

\section{References}

1. World Health Organization. Definition, Diagnosis and Classification of Diabetes Mellitus and its Complications: Report of a WHO Consultation. Part 1: Diagnosis 
and Classification of Diabetes Mellitus. Geneva: World Health Organization; 1999.

2. Baker IDI Heart and Diabetes Institute. Diabetes: the silent pandemic and its impact on Australia. Melbourne: Baker IDI Heart and Diabetes Institute; 2012

3. Wilmot E, Idris I. Early onset type 2 diabetes: risk factors, clinical impact and management. Ther Advances Chronic Dis. 2014;5(6):234-44.

4. Colagiuri R, Dain K, Moylan J. The global response to diabetes: action or apathy? MJA. 2014;201(10):581-3.

5. International Diabetes Federation. IDF Diabetes Atlas. In: Seventh Edition edn. Brussels: International Diabetes Federation; 2015.

6. Gonz lez E, Johansson S, Wallander M, Rodriguez L. Trends in the prevalence and incidence of diabetes in the UK: 1996-2005. J Epidemiol Community Health. 2009;63:332-6.

7. Mokdad AH, Ford ES, Bowman BA, Nelson DE, Engelgau MM, Vinicor F, Marks JS. Diabetes trends in the U. S.: 1990-1998. Diabetes Care. 2000;23:1278-83.

8. Shaw J, Sicree RA, Zimmet PZ. Global estimates of the prevalence of diabetes for 2010 and 2030. Diabetes Res Clin Pract. 2010;87(1):4-14.

9. McCarthy MI. Genomics, Type 2 Diabetes and Obesity. N Engl J Med. 2010; 363:2339-50.

10. Song SH, Hardisty CA. Early-onset Type 2 diabetes mellitus: an increasing phenomenon of elevated cardiovascular risk. Expert Rev Cardiovasc Ther. 2008;6(3):315-22.

11. Hillier TA, Pedula KL. Complications in Young Adults With Early-Onset Type 2 Diabetes. Diabetes Care. 2003;26:2999-3005.

12. Smith TLS, Drum ML, Miernik J, Fogelfeld LA, Lipton RB. Early and Later Onset Type 2 Diabetes in Uninsured Patients: Clinical and Behavioral Differences. J Health Care Poor Underserved. 2008;19(4):1119-35.

13. Soon HS, Gray TA. Early-onset type 2 diabetes: High risk for premature diabetic retinopathy. Diabetes Res Clin Pract. 2011;94(2011):207-11.

14. Aguilar-Salinas CA, Rojas R, Gómez-Pérez FJ, García E, Valles V, Ríos-Torres JM, Franco A, Olaiz G, Sepúlveda J, Rull JA. Prevalence and Characteristics of Early-Onset Type 2 Diabetes in Mexico. Am J Med. 2002;113:569-74.

15. Chuang L-M, Soegondo S, Soewondo P, Young-Seol K, Mohamed M, Dalisay E, Go R, Lee W, Tong-Yuan T, Tandhanand S, et al. Comparisons of the outcomes on control, type of management and complications status in early onset and late onset type 2 diabetes in Asia. Diabetes Res Clin Pract. 2006;71:146-55.

16. Hiller TA, Pedula KL. Characteristics of an adult population with newly diagnosed Type 2 diabetes: The relation of obesity and age of onset. Diabetes Care. 2001;24:1522-7.

17. McQuaid S, O'Gorman DJ, Yousif O, Yeow TP, Rahman Y, Gasparro D, Pacini G, Nolan J. Early-Onset Insulin-Resistant Diabetes in Obese Caucasians Has Features of Typical Type 2 Diabetes, but 3 Decades Earlier. Diabetes Care. 2005;28(5):1216-8

18. Braun B, Zimmermann MB, Kretchmer N, Spargo RM, Smith RM, Gracey M. Risk factors for diabetes and cardiovascular disease in young Australian aborigines. A 5-year follow-up study. Diabetes Care. 1996;19(5):472-9.

19. Zimmet P. Diabesity in Australia: An Affair of the Heart. Heart Lung Circ. 2003;12 Suppl 2:S95-8.

20. Currier D, Pirkis J, Carlin J, Degenhardt L, Dharmage SC, Giles-Corti B, Gordon I, Gurrin LC, Hocking J, Kavanagh AM et al. The Australian Longitudinal Study on Male Health - Methods. BMC Public Health. doi: 10.1186/s12889-016-3698-1.

21. Australian Bureau of Statistics. Australian Statistical Geography Standard (ASGS). Canberra: Australian Bureau of Statistics; 2011.

22. Ten to Men: The Australian Longitudinal Study on Male Health - Data Documentation [http://www.tentomen.org.au/index.php/Researchers/datadoc.html]. Accessed 10 Aug 2015.

23. About the Australian Health Survey [http://www.abs.gov.au/ausstats/abs@. nsf/Lookup/4364.0.55.003Chapter1002011-2012]. Accessed 11 Feb 2016.

24. Australian Bureau of Statistics. Table 8 Selected long-term health conditions by age and sex - Australia. In: 4364055003 - Australian Health Survey: Updated Results, 2011-2012. 2013 edn. Canberra: Australian Bureau of Statistics; 2013.

25. Australian Institute of Health and Welfare (AlHW). The Active Australia Survey: a guide and manual for implementation, analysis and reporting. Canberra: AlHW; 2003.

26. Ware JE, Kosinski M, Keller SD. A 12-Item Short-Form Health Survey: Construction of Scales and Preliminary Tests of Reliability and Validity. Medical Care. 1996;34(3):220-33.

27. Cummins RA, Eckersley R, Pallant J, Van Vugt J, Misajon R. Developing a National Index of Subjective Wellbeing: The Australian Unity Wellbeing Index. Soc Indic Res. 2003;64(2):159-90.
28. The International Wellbeing Group. Personal Wellbeing Index. 4th ed. Melbourne: Australian Centre on Quality of Life, Deakin University; 2006.

29. Census for a brighter future. [http://www.abs.gov.au/census]. Accessed 25 May 2015.

30. Chen L, Magliano DJ, Balkau B, Colagiuri S, Zimmet PZ, Tonkin AM, Mitchell P, Phillips PJ, Shaw JE. AUSDRISK: an Australian Type 2 Diabetes Risk Assessment Tool based on demographic, lifestyle and simple anthropometric measures. Med J Aust. 2010;192(4):197-202.

31. Abouzeid M, Philpot B, Janus ED, Coates MJ, Dunbar JA. Type 2 diabetes prevalence varies by socio-economic status within and between migrant groups: analysis and implications for Australia. BMC Public Health. 2013;13: 252.

32. Tapp RJ, Dunstan DW, Phillips P, Tonkin A, Zimmet PZ, Shaw JE. Association between impaired glucose metabolism and quality of life: Results from the Australian diabetes obesity and lifestyle study. Diabetes Res Clin Pract. 2006; 74:154-61.

\section{Submit your next manuscript to BioMed Central and we will help you at every step:}

- We accept pre-submission inquiries

- Our selector tool helps you to find the most relevant journal

- We provide round the clock customer support

- Convenient online submission

- Thorough peer review

- Inclusion in PubMed and all major indexing services

- Maximum visibility for your research

Submit your manuscript at www.biomedcentral.com/submit
Biomed Central 